\title{
Surplus and Indicator
}

\author{
KATIE VANN
}

\begin{abstract}
This essay offers a perspective on journal impact factor (JIF) centrism in academic evaluation from the vantage point of academic publishing in an increasingly data-driven scholarly environment. The political implications and orientations to the JIF are thought through with respect both to commercial publishing industry consolidation and to the reliance of public-sector scholarly communities on (oligopolistic) commercial academic publishing houses. The author proposes that centrism to the JIF as a legitimizing indicator and incentivizing norm leads to two diametrically opposed forms of "surplus": for academic communities, surplus emerges in the form of layers of scholarly knowledge effects/impact and labor, which, because they remain foreclosed to formal professional recognition, are inadvertently reconstructed as dispensable (waste); for private sector publishing companies-whose contribution to the publishing process consists foremost in providing scalable content management/distribution platforms and in transforming unique manuscript content into standardized digital objects that are amenable to indexing, aggregation, and comparative calculation--surplus emerges in the form of monetary surplus (profit). The essay describes the inner workings of these phenomena.
\end{abstract}

\section{Keywords}

scholarly publishing; indicators; academic evaluation; academic labor; recognition; political economy of publishing; publishing platforms

\section{Introduction: The Indicator}

The Journal Impact Factor (JIF) is a measurement of journal citation counts that is published by Thomson Reuters (TR) each year. Here is the formulation, as shown in the recently published 2015 TR Report received by the journal ST\&HV:

${ }^{1}$ Katie Vann, Email: vannres@gmail.com

Copyright (C) 2017 (Katie Vann). Licensed under the Creative Commons Attribution Non-commercial No Derivatives (bync-nd). Available at estsjournal.org. 


\begin{tabular}{|c|c|}
\hline Term & Definition \\
\hline $\begin{array}{l}\text { Impact } \\
\text { Factor }\end{array}$ & $\begin{array}{l}\text { Average number of times articles from the journal published in the past two years have been cited in } \\
\text { the JCR year. Impact Factor for } 2015 \text { is calculated as follows: } \\
\text { Cites in } 2015 \text { to citable articles published in } 2013 \& 2014 \\
\text { Number of citable articles published in } 2013 \& 2014 \\
\text { (Note: only citations appearing in ranked journals are used in the calculation.) }\end{array}$ \\
\hline
\end{tabular}

It's a simple calculation-fairly primitive and inert on its own-that creates a stir within academic communities. Part of the stir comes from some scholars' belief that the calculation is too crude to capture with any accuracy the true impact that scholarly publications actually make, and in response some folks set out to create more accurate calculations of publication impact. Another aspect of the stir stems from the extent to which various academic evaluators (tenure/promotion/hiring committees, grant funding reviewers. etc.) can be considered JIFcentric, in that they count on the JIF of the journals in which a scholar publishes to indicate the quality of a scholar's past and likely future activity. The reasoning is as simple as the calculation itself: citations in one paper, to another paper, are an indication of the latter's "impact" on the former; the more that happens to the papers in any given journal (the more its papers are cited by other papers), then the greater the impact of that journal must be; and if a scholar publishes in journals with a high JIF, then that scholar must be doing, and will likely continue to do, a fine job. And what JIF-centric evaluators then say is, we are going to hire new talent, allocate university and grant funds, and give tenure promotions to scholars who publish in high-JIF journals.

The problematic character of JIF-centrism is connected to the ostensible crudeness of the JIF calculation in the sense that they co-occur, but the centrism is neither reducible to nor can be transcended by making the calculation more accurate--or so I propose. The problem isn't in the calculation, in other words, but in the centrism, and I am going to try to describe that multifaceted problem here. I want to offer a perspective on an environment in which JIFcentrism prevails. In that environment, the JIF as "indicator" doesn't just show (indicate) other things; it also becomes an incentivizing norm that has effects in its own right, effects that when fully appreciated might want to be taken into consideration by those who lead and manage academic organizations. Specifically, in elevating it to an incentivizing norm, evaluative practices that lean heavily on this "indicator" create conditions for three forms of what I will here call a "surplus."

'See Garfield (2006) for a retrospective piece on the creation of the JIF. It includes a description of the JIF's calculative parameters and rationale as well as Garfield's cautions about using the measure as an evaluation tool. 
(I) In the realm of academic labor financed by public sector money, indicatorcentric evaluation gives rise to surplus in the form of waste with respect to

(i) scholarly knowledge effects (intellectual impact) and

(ii) scholarly contributions / labor

(II) In the realm of private-sector publishing companies that provide services to the public-sector academic communities, indicator-centric evaluation gives rise to surplus in the form of profit at the site of

(iii) operating margins/financial reserves

By "surplus" I generally mean something along the lines of a functional definition, as in, "that which is beyond what is required to realize the objectives at hand." And as I will try to show, while within the broader context of a data-driven, commercial publishing environment each of these forms of surplus creation follow from the prevalence of the indicator as the litmus for evaluators' decisions, they have very different implications for academic communities funded by the public-sector, on one hand, and private sector publishing service enterprises, on the other: academic communities incur significant losses (effectively, because significant knowledge effects and scholarly contributions are foreclosed to recognition and thereby transformed from valuable resources into waste), while private sector publishing enterprises incur significant gains (in the form of money and capital to better position themselves within an increasingly consolidating industry). The situation is a tragic one, because it entails profound losses for academic communities and public sector interests in spite of what must surely be the very best intentions of those evaluators who would heavily rely on the JIF as a fair and objective means of discerning the value of scholarly activity.

Tragedies can be rewritten.

A few words about my position before proceeding, though, because I am no longer an active scholar directly evaluated by reference to the JIFs of the journals in which I publish. Instead, I am the managing editor of two STS journals, one of which-STEHV-has a JIF, and the other-ESTS—does not." So the titles I manage are, either in fact or in principle, subject to getting a JIF and, by extension, capable of bestowing qualities, which are subject to evaluation decisions, to the articles that we publish and their authors.

\footnotetext{
${ }^{3}$ It is the nature of private sector enterprises that they cannot provide services at cost--that is, their entire reason for being is predicated on the realization of surplus value/profit. There's nothing inherently bad about that; the problem arises when that surplus is founded on the losses of public sector organizations that have become dependent on private sector services, and when that surplus is put to work in consolidating the foundations for further dependence.

- Science, Technology, and Human Values (STEHV) is a $40+$ years and going subscription journal that is published by SAGE publishing, and sponsored by the Society for Social Studies of Science (4S); it is on the Reuters Index and has what is in our field considered to be a healthy JIF. Engaging Science, Technology, and Society (ESTS) is an open access journal published by the Society for Social Studies of Science (4S), launched in 2015; it isn't on the Reuters Index and therefore does not have a JIF. After several years as a scholar, I began working as a managing editor in 2008 (with STEHV); prior to that and while still a scholar I was a member of the editorial collective of the journal ephemera: theory and politics in organization.
} 
As managing editor my responsibility is to ensure that our journals thrive, that is, serve our community of scholars in accordance with the objectives set out by our editors and the governance council of the Society for Social Studies of Science (4S). Neither 4S Council nor editors with whom I have worked have ever pressured me to do things to increase or artificially inflate our JIF; nor, as far as I know, is my own performance evaluated with explicit reference to it. Yet it must also be said that in a roundabout way a healthy and/or improving JIF is a good thing, because by and large it makes our journal an attractive publishing venue for STS authors, which is important to us. I will discuss this more later on in the paper, but here I'll say that to the extent that the JIF matters to and for our authors, it matters to and for me. By the same token, our journals' JIF will always be contingent upon the citation practices of scholars and how TR calculates them; and the importance of our JIF score will always be contingent upon the prominence and legitimacy attributed to it through the practices of academic evaluators. To be sure, in the end we may find that the JIF is a purely ideological form in that it matters to anybody only because they believe it matters to everybody else.

As a managing editor I am responsible for tasks that stretch across the publishing process-from pacing and coordinating peer review, to manuscript development and publication schedules...to cultivating relationships and commitments with our reviewers...to developmental editing and copyediting of our publications...to coordinating and troubleshooting processes and information systems that undergird our work. There are some interesting differences in the work I need to do get STEHV and ESTS published, because the two titles have very different ownership structures and organizational and technological substrates. Those differences illuminate dimensions of academic publishing that I believe are pertinent to our understanding of "the indicator game," and so my comments will reflect that standpoint; I confine my focus to STS publishing because that is the only scholarly field within which I currently work.

\section{Where the Surplus is Wasted Knowledge and Wasted Time}

To those who would regard the JIF as resounding evidence of scholarly impact, I will offer the idea that the JIF"s conflation of "citation" and "impact" profoundly misconstrues how reading, and the texts STS scholars read, figure in the formation of STS expertise, and how that expertise is expressed in STS knowledge production. The measure recognizes only those citations made within a two-year and/or a five-year time horizon, and only those citations that appear in journals already included in TR's Web of Science Index. These are somewhat "technical" downfalls of the calculation, which are important, but the problem goes deeper: the ways in which the JIF is currently interpreted as an indication of impact problematically presumes and implies that the knowledge effects of a scholarly text are expressed in some strangely mechanical by citations in the first place. This is bound to give rise to "false negatives" that ultimately create a distorted image of what is happening when STS scholars write. Not because STS is interdisciplinary, but rather because, in accordance with the social phenomena that it studies, STS is methodologically inclined to be ideographic, diachronic, inductive, and problem-focused. The matters under its scrutiny tend to be peculiar to a place and time--moving targets (or butterflies) 
in a process of transformation as they are being elucidated. This makes STS distinctive in relation to relatively cumulative, nomothetic scholarly inquiries (even within the social sciences) such as those that must have figured in the creation of the JIF as an indicator of impact in the mid-1950s. ${ }^{5}$ Couple with that the imperative for STS scholars to read against the grains of power, naturalization, and common sense (which in my view distinguishes STS scholarship from other literature whose subject matter also happens to be "science" and / or "technology"), and you have a discipline whose capacities to carry on in meaningful ways cannot be reduced to being informed/impacted by a narrow corpus of "the latest and most up to date findings" about some ostensibly timeless and law-like phenomenon. Rather, STS scholars must draw from a literature of far greater breadth and historicity--a vast reservoir of sensitizing concepts that are always simmering under the STS scholar's belt, waiting to be drawn upon in accordance with the phenomena at hand. STS researchers who contribute truly meaningful insights for the field make analytical and representational decisions on the basis of such a broad reservoir of literatures with which they must know how to think; effective STS writers make decisions about which of them to leave out; and expert scholars do both.

Of course, texts are "tools" that can be "used" in a narrowly instrumental manner within the context of a particular paper-and this seems to be the reasoning behind using citations as indicators of impact-but at their best and in their capacity to have meaningful and dynamic knowledge effects for the field, STS texts are better understood as environments in and through which STS minds grow and take shape. To presume that the generative features of those environments are "indicated" only in citations that appear in other papers (in other words, to confuse any text's citation by other papers for its knowledge effects) is effectively to suggest that what isn't cited hasn't really mattered, and won't. And when the indicator acknowledges the knowledge effects only of that which is cited-and creates incentives only to be cited or "appear" in highly cited journals-this vast other field of knowledge impacts emerges, relationally, as that which is far beyond what is required, as a field of surplus, superfluous knowledge, waste.

So scholars are rightly concerned about JIF-centric evaluation, because they grasp that the process underlying the creation of the citation data calculated rests upon citation practices that are themselves properly and highly contingent and far from mechanical in character. The impact of the texts they publish thus may be deeply understated (or overstated) depending on the citation practices of others and how those are calculated. That's a potential problem for individual scholars in that evaluators might not grasp the impact they are truly making; but from where I sit it appears to be a problem for STS communities more broadly construed, because indicator-centrism may actually wind up actively devaluing much of what scholars contribute to and draw upon as constituent literatures of and for the field. All that knowledge not recognized. Gone to waste.

${ }^{5}$ See Garfield 2006 for a discussion of how and why they did it.

"Apropos, two points: some influential papers in the field (highly cited and otherwise) are themselves written by citation minimalists; and some papers may cite maximally in a "sound bite" sort of way, yet can be said to demonstrate that their referenced works do not appear to have made a substantive difference for their analysis. 
I just can't imagine how a community can thrive when it undergoes a protracted process of turning its own contributions and social resources into waste. But the culprit here seems to be an underlying reliance on comparable, aggregate data as a stand-in for other modes of discernment and judgment with respect to what matters for the community's knowledge production activities. Reliance on the JIF in particular is just a socially evolved (because it is so widely utilized) instance of this more general phenomenon. For instance, recently I received an email from a tenured professor whose work we had published, with the subject heading "ESTS Download Statistics?" It said:

\begin{abstract}
Dear Katie,
I'm wondering whether ESTS has any statistics on article downloads. My institution is going to give me a hard time for publishing in a new open-access journal, and it would be great to respond with some measures of impact (if indeed there is any sign of impact, that is....) I put the link up on Academia.edu and it's been in the top 4\% two month in a row; I'd love to be able to add some journal measures too. Regardless of stats and begrudging institutions, I'm very grateful to you and to ESTS for putting it out. It's the best publication experience I ever had.

With all my best, xoxo
\end{abstract}

This is a low-key version of a kind of email I receive regularly from authors of both STEHV and ESTS. Scholars are looking for data to give to somebody else who will think the data is important in the decisions they need to make about the scholar's work. Since the code for such a report exists in the open-source platform called Open Journal Systems (OJS) that we use for ESTS, I was able to send this author a view of spreadsheet data that showed all the papers ESTS had published and how many times each of them had been downloaded. But as I prepared my note to her the banal truth struck me that the "institution" (presumably some people and some conduct protocols of some sort) had given her the impression that it cared less about what she had written (or indeed about any judgments "it" might make about that writing) than about obtaining information about whether other people thought it was worth the time to click a download button. And sadly I accepted that it is probably an instance of a more general phenomenon of data deferral - a social practice through which the rendering of scholarly activity as data had come to eclipse the intellectual content of scholarly works as such. ' Given what I noted above about citation practices and the relational emergence of knowledge impacts as waste, the intensification of data deferral might mean that waste within academic communities will increase. And it certainly suggests that academic communities are increasingly dependent both upon the generation of data about their own practices and upon those who provide data-generation

\footnotetext{
- From this standpoint, I think attempts to improve on the impact factor by tweaking its calculative parameters may be chasing a red herring. Citation as such is not a good indicator of the generative knowledge effects of a text that a scholar might produce (or, it is not an indicator of "impact" in the sense evaluators seem to conceive it). Thus, I back efforts to encourage evaluators to simply try to take a much broader and more balanced view of scholarly activity when figuring out to do with their resources.
} 
services. I will return to this point below because it has direct bearing on the creation of financial surplus in the operating margins of private sector publishing companies.

In addition to its tendency to emphasize citation data and thereby render intellectual content that has not become data as waste, though, JIF-centric evaluation probably also gives so much weight to publishing as such that it may render a range of other scholarly activities as waste as well. Because taking something on which you rely for granted is worlds away from meaningfully recognizing its importance. And by not recognizing those other activities--which include reading-focused endeavors such as teaching and thinking about and reviewing colleagues' papers in order to improve the work of the community broadly construed--JIFcentric evaluation might just telegraph the message to everyone that those other features of scholarly activity are not to be recognized as part of the core business of scholarly work. We can call all those other activities "invisible labor," if we choose, though today that wouldn't be my choice.

Because there's nothing invisible about them. Take reviewing articles. That labor isn't "invisible" to all the people who are reviewing papers; it isn't invisible to all the authors who are learning from the reviews; it isn't invisible to my editors and me; and it needn't be invisible to evaluators. "Invisible" gives that work some kind of mystical aura and strangely reifies the contingent and contested social process through which the "indicator" of valued and worthwhile activity simply cuts it out of evaluators' line of sight. In a weirdly platonic, camera obscura kind of way it recalls what was noted about the SIGN: "Such is the strange being of the sign: half of it is always 'not there' and the other half always 'not that'" (Spivak 1976, xvii). And when such a sign is elevated to the position of "seeing" or "knowing" scholarly practices for us (think "data"), it thereby also creates its own spaces of darkness (or alterity) that are simultaneously disavowed (or made to appear absent-aka "invisible") and constitutive of the presence (or the "visible") that the indicator will have made manifest.

So "invisible labor" is not so much a substantively peculiar type of human activity (as would be suggested were the conceptual category to be conflated with another, such as "tacit labor"), as it is an emergent manifestation of the optics of recognition occurring across a social field. Derridean's might call such invisible labor a "trace"; here I call it "surplus." And in elevating JIF publishing to such a high pedestal-as JIF-centrism is prone to do--isn't that a silent way of saying that those other activities are more than what is needed, a kind of excess, and maybe even a waste of time? And might scholars learn to agree?

It is already taking place to some degree, I think, based on the increasing frequency with which scholars reply with a "no" to our invitations to review a paper and say that, because their funders want them to focus on publishing, they can't review papers. When I read such "no" replies, I'm torn: is the "no" self-seeking, or is it smart? And then I step back and realize that there are actually contradictory imperatives floating around the community--a classic Batesonian double-bind. (Do I need to say that if everybody with funding refused to review papers there'd

s This is due not to the anonymity of peer review but rather to the paltry weight that indicator-driven evaluation gives to the activity of reviewing manuscripts. 
be no peer-reviewed publishing?). This is an irrational ${ }^{10}$ situation for scholarly communities--and quite possibly for the evaluators themselves--because the authors (whose publishing the evaluators hope to recognize and incentivize) and the reviewers (whose scholarly practices the evaluators are not recognizing and thereby dis-incentivizing) are the same people... and JIFqualified "publication" relies on them both. Seen in this light, JIF-centric evaluation actively, if not consciously, creates within one community two social force fields that work against each other, or, a community divided against itself.

\section{Swerve}

But here I'll go, being all ideological, and say I'm pleased when STEHV's JIF increases. Because if we have a JIF anyway, and it has bearing on the professional stability of our authors, would we really want it to go down? No, because the better our JIF, the better for all the authors who publish with us, even if it wasn't citations to all their papers that led to the increase. That's a lot of honey for the group, and it's a kind of collective qualification process that I find far more politically interesting than other, relatively individualizing qualification possibilities that are pursued by the alt-metrics community. Furthermore, and subject to the input of my editor and $4 S$ Council, I'm inclined to do the footwork required for ESTS to be included on the TR index as soon as possible, so that it can start getting a JIF." My inclination is tempered by the fact that some in the STS community have expressed to me the need to jettison the JIF through both active and passive boycotts, suggesting that by participating with the "impact factor regime" I bolster it, enacting a kind of "conservatism" that should cease.

They are right, of course, but their tactics might not exhaust possibilities for getting out of this pickle; for I also know that making choices about how to cope with "the regime" is a lot like being the ball on the surface of a pinball game: any move you make in response to one problem immediately propels you into and ricochets you off another. This is what it means to be implicated in the indicator game (Fochler and de Rijcke 2017): we're not playing a game that is separate from ourselves; we're inside and part of it, and so are a lot of other things and people. Private sector academic publishers with proprietary gates around the JIF'd content they distribute are one of the other bumpers in our pinball game, and I worry that efforts to boycott the JIF might steer emerging STS journals that want to remain independent from commercial publishers from attempting to be included in the JIF index. While appearing to constitute a progressive transformation, that may wind up ceding legitimacy to private sector publishers, bolstering their further consolidation in an already oligopolistic industry (Larivière et al. 2015), increasing publicsector reliance on their services, and hindering the creation of alternative futures for non-profit

\footnotetext{
- To be sure, the current situation creates ripe conditions for the emergence of a slow-motion work-to-rule strike that nobody even realizes is happening but could nevertheless cripple scholarly organizations.

"By "irrational" in this context I mean something like "not in accordance with collective interests of scholarly communities."

"This will involve submitting an application to be considered among about 2,000 other applications; the annual acceptance rate is about $10 \%$.
} 
scholarly publishing. Because in the current data-centric evaluation environment, JIFqualification enhances a journal's brand in ways that can give it legitimacy vis-à-vis those without it; and so, without knowing in advance whether those evaluation practices could be transformed any time soon, in effect the risks to emerging scholarly publishing futures need to be kept in simultaneous, relational play with the limitations of JIF as a recognition technique.

Though the analogy is limited, I am informed on this point by discussions around efforts to extend marriage rights to same-sex couples. When positioned within a broader institutional recognition framework through its primacy in academic evaluation, the JIF of a journal in which an author publishes has a way of conferring identity to him, much in the way that the performative utterance "I now pronounce you" at the core of state-sanctioned marriage confers identity to the individuals in a couple: it essentially utters, "I pronounce this work to be of importance and of high quality." " Insofar as such an identity is closely linked with the distribution of social resources in a way that is exclusionary, as is the case both with the bestowal of state-sanctioned marriage rights and with JIF-centric hiring/tenure/grant decisions, the question arises whether it is better to broaden the social field to which such identity and recognition can be conferred (even homosexuals can get married to each other; even new noncommercial journals can get a JIF), or, rather, to forsake the mode of recognition that confers it in the first place (forget marriage; forget the JIF).

Judith Butler put this in an interesting light when she said, "I agree that the right to homosexual marriage runs the risk of producing a conservative effect, of making marriage an act of normalisation, and thereby presenting other very important forms of intimacy and kinship as abnormal or even pathological. But the question is: politically, what do we do with this? I would say that every campaign in favour of homosexual marriage ought also to be in favour of alternative families, the alternative systems of kinship and personal association. We need a movement that does not win rights for some people at the expense of others. And imagining this movement is not easy" (see Birulés 2009).

The analogy with which I am playing involves viewing non-profit/open access publishing as a potential space for the creation of alternative modes of scholarly association, which may depend less on jettisoning the JIF (indeed it might leverage it) than on rethinking another, related issue: the rational ${ }^{13}$ organization and uses of scholarly resources. This idea requires further consideration of the organization of private sector/commercial academic publishing in its current relations with JIF-centric academic evaluation practices.

We know that JIF-centric evaluation shapes many scholars' decisions about where to publish. A growing body of research shows this in numerous fields and we here at our journals hear it from STS scholars. In our cases: ESTS might be a risky career choice because it has no JIF ("an ESTS paper won't count when I go up for tenure $\otimes^{\circ}$ ") and STEHV is a smart career choice because it does ("I really need this ST\&HV paper on my grant report, now!"). And some people

"2 Note that the performative efficacy of the utterance doesn't hold in the case of marriage unless it is backed by the legitimating, state-sanctioned paper. The TR index data fulfills a similar legitimating function.

${ }_{13}$ By "rational" in this context I mean something like "in accordance with collective interests of scholarly communities." 
seem to think that new journals, particularly those that are open access, are plebian projects that won't ever have a JIF, which is a misconception that nevertheless drives manuscript submission to established, subscription journals-an increasing number of which are published by private sector publishers. When this phenomenon is coupled with the fact that JIF-centric evaluation creates incentives for scholars not only to publish in JIF journals, but also to publish lots of JIFqualified publications, something else begins to take shape: the "audit explosion" (Power 1994) becomes what I'll call the "JIF publishing explosion." The incentive to publish in particular venues is embedded in the auditing practices and thereby drives broader, related effects in publishing practices. We are already seeing steep increases in the volume of submissions to commercially published STS journals (for example, Social Studies of Science; STEHV; Public Understanding of Science-all in the SAGE portfolio--though there are several others in the portfolios of other very large academic publishers such as Reed-Elsevier, Wiley-Blackwell, Springer, and Taylor \& Francis). This is partly due to the expansion of our field in terms of headcount, but it is also due to the increasing prevalence of incentives for any given head to publish more JIF-qualified articles. And with respect to the political-economics, I want to direct attention to the way in which rises in publication submissions have very different consequences for scholarly communities, on one hand, and private sector publishers, on the other. (Here is where our distinction between forms of surplus will be thrown into relief.)

For scholarly communities, the effect is increased demand for reviewer labor, which is integral to the process of scholarly content development and indeed a condition of that content's JIF-qualification. Yet what I have tried to show in the previous section is that such labor is an instance of scholarly activity that, in not being recognized as a valued scholarly activity in its own right, is implicitly rendered as surplus, or waste, in relation to the indicator."

Which is sad, but it gets worse, because, contrary to the emergent deficits created for public-sector academic communities, the publishing explosion contributes to increases in "operating margin," "surplus value," or "profit" for commercial publishers (see Himmelweit 1983 [1995]; see also Larivière et al. 2015, on which more directly below).

\section{Where the Surplus is Private Sector Profit}

To begin to appreciate how the same indicator centrism can have diametrically opposed effects for public-sector academic communities and private sector publishers, respectively, it is important to parse out a few of the underlying dimensions of publishing as a production process. By "operating margin" (OM) I mean money remaining after subtracting from sales revenue (SR) the costs for operating expenses (OE) and cost of goods sold (COGS). Plainly put, your operating

"Thus the poignancy of Butler's remarks, when she says that marriage normalises "and thereby present[s] other very important forms of intimacy and kinship as abnormal or even pathological." In a similar way, JIF-centric evaluation presents other publication venues as deviations from the norms of scholarly activity that it incentivizes, and it presents forms of scholarly activity other than publishing as a deviation from the norm that it incentivizes. 
margin is what's leftover after your OE's and your COGS are done gnoshing on your sales revenue. Here's a nifty equation to make it look official: $\mathrm{OM}=\mathrm{SR}$ - [OE+COGS].

Examples of OE's are such costs as those incurred for the publishers' managerial and administrative functions, marketing, and asset depreciation; COGS, in contrast, are costs that are directly incurred in production (whether internally or by third-party vendors) of salable goods,

The expenses we need to focus on are the costs of goods sold (COGS), which, in a commercial publisher's case, are those that are tied directly to the production of the articles to which institutional or individual subscribers to a journal obtain access. Examples of COGS are costs incurred for article content development (including the writing, reviewing, developmental editing, copyediting, layout, typesetting, and proofing) and those incurred for metadata fulfillment, archiving and indexing, content management and content distribution. And in order for operating margins to increase, you need to stabilize the COGS in the face of increasing sales revenue (SR): the rising operating margin is the resulting difference-otherwise (if your revenue increases are tightly coupled with increasing costs) there's no meaningful margin increase.

Now, one might expect the publishing explosion to lead to an increase in publishers' COGs; all that content needs to be produced, afterall, which presumably is expressed as added cost. However, given commercial publishers' rising operating margins, our question must be this: how can the COGS that are incurred by them be held in place in the face of the increasing volumes associated with the publishing explosion?

A true and obvious explanation is that a significant portion of the COGS (specifically, for content production activities such as authoring, peer review, development editing and copyediting) are carried out at little to no costs to publishers, because they are by and large undertaken by scholarly communities. That labor, which in this context can properly be identified as third-party vendor services in the content production supply chain, is a legacy practice historically understood to be part of the community "service" undertaken by academics who are presumed to be otherwise stably employed in universities. The JIF-centric publishing explosion significantly increases demand for those services (even if academic evaluation doesn't formally recognize their centrality to publishing), and whatever costs it creates for those academics engaged in it, which though not tallied may be significant, are not incurred by commercial publishers.

Yet something more is happening beyond the use of this so-called "free" academic labor, and it further enables the COGS incurred by commercial publishers to remain stable in the face of the publishing explosion. It has to do with the standardization of manuscript content, and I will try to get to the heart of it by foiling things out through a brief consideration of how it is sometimes said that publishers don't contribute anything of value to the publishing process.

A recent paper by Larivière et al. (2015) describes the formation of an oligopolistic situation that has come to pass in recent decades, in which the profit margins of commercial publishers are increasing in tandem with the consolidation of the industry in a handful of large publishing houses. The details of the paper, entitled "The Oligopoly of Academic Publishers in the Digital Era," should be read by anyone interested in understanding the expanse and intensity of the changes at stake. 
Let us hold in place its findings about industry consolidation and increased profits, while also noting its concluding discussion, where it suggests the following: since the only activities that really add value to published content are authoring, peer review, and editing--to which commercial publishers make no contribution-then commercial publishers do not add any value to the process and therefore their existence in the production chain makes no sense. They write,

The proportion of the scientific output published in journals under their [commercial publishers'] ownership has risen steadily over the past 40 years, and even more so since the advent of the digital era. The value added, however, has not followed a similar trend. While one could argue that their role of typesetting, printing, and diffusion were central in the print world...the ease with which these functions can be fulfilled-or are no longer necessary-in the electronic world makes one wonder: what do we need publishers for? (Larivière et al. 2015, 12).

It is an "emperor has no clothes" story built to critically question the reliance of academic communities on commercial publishers. That's ok, but I disagree with the assessment of the situation and believe its limitations prevent a productive discernment of how to formulate alternatives. Specifically, although it may be true that commercial publishers do not contribute to the intellectual content of scholarly articles, Larivière et al. nevertheless underestimate the dimensions of the publishing production process that commercial publishers do provide. They suggest that activities like typesetting and diffusion are anachronistic and superfluous in "the electronic world." On the contrary, I suggest that, even where print is no longer in play, activities much like typesetting and diffusion are integral to scholarly publishing today, particularly when we appreciate the data-centric context in which scholarly publishing occurs. There's this range of activities that need to be undertaken for the article to come out and sit on the Table of Contents of a journal to be read and, more importantly, to be counted has having been read. Those activities are crucial—even if they might seem like mindless, automated or grunt work compared to what it took to write the paper itself--and they are where large commercial publishers are both making a difference and consolidating their positions in an increasingly oligopolistic industry.

More specifically, I want to propose, the core business of commercial publishers is significant for scholarly publishing and two-fold. First, much like platforms such as Spotify or Amazon, they provide digital infrastructure that mediates at scale exchanges across networks of producers (authors) and consumers (libraries, individual subscribers); second, they transform the array of unique intellectual contents accepted for publication ("manuscripts") into standardized digital objects ("articles" endowed with unique metadata identifiers) that can be distributed across consumption and data-generation networks (libraries, archives, and indexes). Such standardization is a pre-requisite for the aggregation, calculation, and reporting of those articles' lives and how they are "impacting" others. In this respect, I want to suggest that the transformation of manuscript content into standardized digital objects is instrumental in conferring academic value to the scholarly publications and that it is instrumental in stabilizing the COGS incurred by commercial publishers in the face of increasing publication volumes, which ultimately increases their operating margins. Grasping that phenomenon is pertinent to 
consideration of the indicator game, because JIF-centric evaluation occurs throughout the context of a broader ecosystem of academic publishing. I am trying to show how such evaluation leads to different forms of surplus creation for public-sector academic communities (waste) and for private-sector publishers (financial profit), respectively, and appreciating what the latter bring to the eco-system is highly relevant to understanding how that difference comes about.

One way to understand what commercial publishers have achieved is to see it as the articulation of a group of integrated IT sub-systems whose synergies constitute a possibly unprecedented achievement in the control of the means of production (or "constant capital"--see again Himmelweit 1983) in the sphere of scholarly publishing. ${ }^{15}$ The infrastructures that mediate exchange between authors and readers consist in articulated software components provided by a range of third-party vendors [e.g., Thomson Reuters is a provider of the ScholarOne content management; Atypon is a provider of the Literatum content aggregation platform; Highwire provides content aggregation and content distribution], which are drawn together within the sphere of the commercial publisher's ownership, control and utilization. ${ }^{16}$ Articulating such systems requires licensing, systems maintenance, and organizational activities on the commercial publisher's part, and those create COGS that the publisher incurs.

However, an important point is that those costs don't increase step-wise with increases in submission volume, because the publishers only have to do anything to those manuscripts that are accepted for publication; (contrast this with the peer review process, which is required for a far greater proportion of submitted content). Nor do those costs necessarily increase step-wise with an increase in accepted article publication volume (whether within one journal or the through the expansion of a publisher's overall portfolio), because what those articulated systems "process" (and contrary to what occurs within the relatively customized, intellectual content development process undertaken by academic communities) are essentially standardized digital objects: from the articulated systems' point of view all the objects are "the same" data packages (e.g., XML, metadata fields, article PDFs, etc.)." That sameness grounds an economy of scale with respect to the distribution of article content to libraries, indexing organizations, archives, and so on, which is a crucial step in any published article's existence as readable and countable scholarly output. By "economy of scale" in this context I mean that publication volume increases, when tied to revenue increases, are ultimately expressed as reductions in per-unit costs (i.e., costs per article). In Sage's case, nearly 1,000 journals are serviced through the same platform; and the more that number increases-whether through new journal acquisitions or through journalspecific publication volume increases-the cheaper the processing of all that content becomes. That is an important part of how industry consolidation occurs.

\footnotetext{
${ }_{15}$ Readers are invited to explore a recent paper by Langley and Leyshon (2016) that describes and theorizes how such "platforms" work and manifest peculiar political-economic characteristics. I'm not confident the articulated systems utilized by commercial publishers fit fully or neatly into Langley and Leyshon's typology, but I do believe they have some of the core platform characteristics that the authors identify.

${ }_{16}$ The Open Journal Systems platform has some of the functional affordances of the kinds of infrastructures assembled by commercial publishers, but currently it is not as robust or as extensive with respect to what it is able to do.

"Below I describe how intellectual content is packaged to obtain that standardization/uniformity.
} 
Of course, scaling of this sort requires that the unique intellectual content (that text which is submitted and ultimately accepted) gets transformed into the standardized digital objects in the first place. That transformation occurs in a process called "editorial production," wherein bibliographies are checked and corrected for thoroughness and accuracy; wherein manuscript content is formatted to house style; wherein digital object identifiers (DOI's) and other important metadata are assigned; and wherein the resulting formatted PDFs and possibly HTML and metadata are uploaded/input/registered into the appropriate partner systems (for distribution, indexing, and so on). I know how multifaceted and labor intensive that process is, because I do it for all our ESTS publications since we do not work with another publisher that provides those services. For $S T \mathcal{E} H V$, that same work is undertaken by employees working at a SAGE office in India and/or out-sourced to contractors there, where the labor costs are low.

So, returning to the world imagined by Larivière et al., if you are an author who wants to write a paper and make it available in the electronic world for someone to read, none of that standardization is required. (It recalls that you can love deeply without marrying.) And what's interesting is that commercial publishers don't seem to care that much about the open distribution of such unstandardized content anyway, even when some version of it is ultimately accepted in a journal they publish. Thus, for example, SAGE's fairly liberal copyright guidelines, state:

\section{You may do whatever you wish with the version you submitted to the journal} and even that:

$>\quad$ You may post the accepted version (version 2) of the article on your own personal website, but that: your department's website or the repository of your institution without any restrictions

$>\quad$ You may not post the published article (version 3) on a website or in a repository without permission from SAGE

and that:

When posting or re-using the article please provide a link to the appropriate DOI for the published version of the article on SAGE Journals (http://online.sagepub.com)

I mean, in effect, commercial publishers aren't so much concerned with the unique filling (the stuff you read, though they must at some level presuppose that its quality is ensured by journals' reviewers and editors through the peer review process), as with the uniform wrapping (the formalized and registered identity of what you read): the standardized digital object. What they understand is that the value of the article-even for the author-largely consists in the standardized packaging of its identity, ${ }^{\text {, }}$ because that is what is capable of being aggregated and

\footnotetext{
${ }^{18}$ A good example is the assignation of DOI's to articles. The DOI assigned to a particular article has a peculiar syntax that is specific to the associated title and publisher, and it must be registered with another organization, such CrossREF, which is an official Digital Object Identifier Registration Agency of the International DOI Foundation. Relationships between publishing entities and DOI organizations are formalized and organized ones that come with systematicity and rules of conduct that undergird the legitimacy and preservation of the DOI assignment. Such DOI's then become part of the metadata associated with the article, forever part of its identity as an indexed and cited digital object.
} 
counted in a manner that is meaningful to those who are in a position to evaluate the relative value of authors' activity. That's the "version" (but actually it is a standardized identity of the version as such) to which they grant access through the process of subscription. The more generalized social process of data deferral, which I discussed earlier, undergirds the importance of that standardization, and, hence, also contributes to conditions for both the scale-related cost reductions of commercial publishers and the resulting increase in their money surplus, or operating margins.

\section{What Now?}

I offer this perspective with the hope that it will be of some help in understanding the present JIFcentric environment and finding ways to improve upon it. My presentation has outlined ways in which data-centric evaluation gives rise to losses for academic communities: over-reliance on a particular indicator has a way of foreclosing a range of scholarly contributions to recognition of their importance and efficacy in realizing the broader objectives of scholarly activities. That foreclosure renders valuable resources as waste and may have deleterious effects for academic communities over time. Those in academic leadership positions might find that the prospects of those effects make it worthwhile to consider ways of broadening evaluators' lines of sight, even as that broadening may limit the prospects of evaluative objectivity. Because maybe things can be different: what is now rendered waste could become beacons of value in the eyes of leadership.

The presentation has also outlined how data-centric evaluation and the services contributed by commercial publishers fold together in ways that deepen the reliance of publicsector academic communities on those services and further bolster the financial gains of the companies that offer them. The contributions of commercial publishers are very important in this context, and academic communities are not better off failing to recognize that contribution-particularly if they come around to believing that it would be worthwhile to explore alternatives to the oligopolistic situation Larivière identifies (see also Jiménez et al. 2015). Notwithstanding the inverted forms of surplus creation noted above--and holding indicator-centrism as a constant-until academic communities can learn to organize scholarly publishing in a way that will achieve a similar economy of scale and associated stabilization in the cost of goods sold, commercial publishers may continue to appear as a more attractive partner. Academic communities may have much to gain by learning from what those publishers have been able to achieve, finding ways to tool up in ways that enable fresh alternatives.

\section{Acknowledgements}

I really appreciate Sarah DeRijck and Maxamillian Fochler for inviting me to participate in this project and for providing smart and encouraging feedback along the way. They and the other authors involved have been truly wonderful work partners and it is an honor to be engaged with 
them all. I also thank my ESTS editor, Daniel Lee Kleinman, and the reviewers for their insightful comments on a previous draft. Finally, an endless thank you is also sent to Sisse Finken for challenging conversations on this and other topics. The impacts of our kinship linger on.

\section{Author Biography}

Katie Vann is the Managing Editor for the Society for Social Studies of Science. She holds a PhD in Communication from the University of California, San Diego.

\section{References}

Birulés, F. 2009 "Interview with Judith Butler: Gender is Extramoral." Monthly Review. May 16, 2009. http:/ / mrzine.monthlyreview.org/2009/butler160509.html.

DORA. No Date. "San Francisco Declaration on Research Assessment Putting science into the assessment of research." Accessed at http: / / www.ascb.org/ dora/

Fochler, M. and S. de Rijcke. 2017. "Implicated in the Indicator Game? An Experimental Debate." Engaging Science, Technology, and Society 3: 21-40. DOI:10.17351/ests2017.108.

Garfield. E. 2006. "The History and Meaning of the Journal Impact Factor." Journal of the American Medical Association, January 4, 2006. Vol. 295, No. 1. 90-93.

Himmelweit, S. 1983 [1995]). "Surplus Value." In A Dictionary of Marxist Thought, (2 ${ }^{\text {nd }}$ ed), edited by T. Bottomore, 528 - 531. Cambridge, MA: Basil Blackwell.

Jiménez, A. C., J. Willinsky, D. Boyer, G. de Col and A. Golub (2015) “Why an open access publishing cooperative can work: A proposal for the AAA's journal portfolio." HAU: Journal of Ethnographic Theory 5 (2): v - xii.

Larivière V., S. Haustein, and P. Mongeon (2015) “The Oligopoly of Academic Publishers in the Digital Era." PLOS ONE 10(6), 1-15. doi:10.1371/journal.pone.0127502

Langley, P. and A. Leyshon (2106) "Platform capitalism: The intermediation and capitalisation of digital economic circulation." Finance and Society, EarlyView: 1-21

Power, M. 1994. The Audit Explosion. London, UK: Demos Press.

Spivak, G. C. 1976. "Translator's Preface" in Of Grammatology, by J. Derrida, trans. G.C. Spivak, ix-lxxxvii. Baltimore, MA: Johns Hopkins University Press. 